\title{
ON MINIMAL GEODETIC DOMINATION IN GRAPHS
}

\author{
Hearty M. Nuenay ${ }^{1}$ \\ AND \\ FERDINAND P. JAMIL ${ }^{2}$ \\ Department of Mathematics and Statistics \\ MSU-Iligan Institute of Technology \\ Iligan City, Philippines \\ e-mail: ferdinand.jamil@g.msuiit.edu.ph
}

\begin{abstract}
Let $G$ be a connected graph. For two vertices $u$ and $v$ in $G$, a $u-v$ geodesic is any shortest path joining $u$ and $v$. The closed geodetic interval $I_{G}[u, v]$ consists of all vertices of $G$ lying on any $u-v$ geodesic. For $S \subseteq V(G), S$ is a geodetic set in $G$ if $\bigcup_{u, v \in S} I_{G}[u, v]=V(G)$.

Vertices $u$ and $v$ of $G$ are neighbors if $u$ and $v$ are adjacent. The closed neighborhood $N_{G}[v]$ of vertex $v$ consists of $v$ and all neighbors of $v$. For $S \subseteq V(G), S$ is a dominating set in $G$ if $\bigcup_{u \in S} N_{G}[u]=V(G)$. A geodetic dominating set in $G$ is any geodetic set in $G$ which is at the same time a dominating set in $G$. A geodetic dominating set in $G$ is a minimal geodetic dominating set if it does not have a proper subset which is itself a geodetic dominating set in $G$. The maximum cardinality of a minimal geodetic dominating set in $G$ is the upper geodetic domination number of $G$. This paper initiates the study of minimal geodetic dominating sets and upper geodetic domination numbers of connected graphs.
\end{abstract}

Keywords: minimal geodetic dominating set, upper geodetic domination number.

2010 Mathematics Subject Classification: 05C12.

\section{REFERENCES}

\footnotetext{
${ }^{1}$ Research is fully supported by the Department of Science and Technology, Philippines, through the Accelerated Science and Technology Human Resource Development (ASTHRD) Scholarship Program.

${ }^{2}$ Corresponding author.
} 
[1] S. Canoy Jr. and G. Cagaanan, On the geodesic and hull numbers of graphs, Congr. Numer. 161 (2003) 97-104.

[2] S. Canoy Jr. and G. Cagaanan, On the geodetic covers and geodetic bases of the composition $G\left[K_{m}\right]$, Ars Combin. 79 (2006) 33-45.

[3] G. Chartrand, F. Harary and P. Zhang, Geodetics sets in graphs, Discuss. Math. Graph Theory 20 (2000) 129-138.

doi:10.7151/dmgt.1112

[4] G. Chartrand, F. Harary and P. Zhang, On the geodetic number of a graph, Networks 39 (2002) 1-6. doi:10.1002/net.10007

[5] I. Aniversario, F. Jamil and S. Canoy Jr., The closed geodetic numbers of graphs, Util. Math. 74 (2007) 3-18.

[6] S. Canoy Jr., G. Cagaanan and S. Gervacio, Convexity, geodetic and hull numbers of the join of graphs, Util. Math. 71 (2007) 143-159.

[7] S. Canoy Jr. and I.J. Garces, Convex sets under some graph operations, Graphs Combin. 18 (2002) 787-793. doi:0.1007/s003730200065

[8] H. Escuardo, R. Gera, A. Hansberg, N. Jafari Rad and L. Volkmann, Geodetic domination in graphs, J. Combin. Math. Combin. Comput. 77 (2011) 89-101.

[9] T. Haynes, S.T. Hedetniemi and P. Slater, Fundamentals of Domination in Graphs (Marcel Dekker, Inc. New York, 1998).

[10] T. Haynes, S.M. Hedetniemi, S.T. Hedetniemi and M. Henning, Domination in graphs applied to electrical power networks, SIAM J. Discrete Math. 15 (2000) 519529 . doi: $10.1137 /$ S0895480100375831

[11] F. Buckley and F. Harary, Distance in Graphs (Redwood City, CA: Addison-Wesley, 1990).

[12] M. Lemańska, Weakly convex and convex domination numbers, Opuscula Math. 24 (2004)) 181-188.

[13] J. Bondy and G. Fan, A sufficient condition for dominating cycles, Discrete Math. 67 (1987) 205-208. doi:10.1016/0012-365X(87)90029-X

[14] E. Cockayne and S.T. Hedetniemi, Towards a theory of domination in graphs, Networks 7 (1977) 247-261. doi:10.1002/net.3230070305

[15] H. Walikar, B. Acharya and E. Samathkumar, Recent Developments in the Theory of Domination in Graphs (Allahabad, 1979).

[16] T.L. Tacbobo, F.P.Jamil and S. Canoy Jr., Monophonic and geodetic domination in the join, corona and composition of graphs, Ars Combin. 112 (2013) 13-32. 
Received 28 December 2013

Revised 25 June 2014

Accepted 1 August 2014 